\title{
EFFECT OF LIFE CYCLE OF A RIB SUPPORTED COMPONENT BY FILLET RADIUS ON THE HIGH CYCLE FATIGUE LOADING: A CASE STUDY
}

\author{
Naga Sai Ram Gopisetti ${ }^{1}$, Sudhanshu G Chouhan ${ }^{2}$, Akhil V S R Palakurthi ${ }^{3}$ \\ ${ }^{1}$ Under Graduation Student, Mechanical Engineering Department, $K$ L University, Andhra Pradesh, India \\ ${ }^{2}$ Under Graduation Student, Mechanical Engineering Department, K L University, Andhra Pradesh, India \\ ${ }^{3}$ Under Graduation Student, Mechanical Engineering Department, K L University, Andhra Pradesh, India
}

\begin{abstract}
Convectional product design or the machine design often deals with the perfect shapes and geometries where the analysis is useful for determining the fatigue cycle. It is most seen in while designing the life cycle of the product or the total number of the cycles that the product can withstand for the given load, modifications in the geometries will give a shuttle change in the total number of cycles, or the change of the material. The following studied is made upon the effect of continues fillets of the ribbed supported component with the soderberg design criteria in the fully reversed analysis. It is not possible to model this geometry with the convectional formulation so FEA is used for the fatigue analysis. It is found that the with the increase of continues fillets there is change in the number of life cycles so as the test loads related as inversely.
\end{abstract}

Keywords: Product Life Cycle, Continuous Fillet, Ribbed Support Component, FEA

\section{INTRODUCTION}

Machine design often plays the important role in the decision factor of the product. Good product means not only the machine but also the domestic and household and everyday electronics. The real beauty of this concept is that the wide spread of the way the dimensions and appearance that will affect the performance of the product. The realtime application is say industrial design and product design and cross platform visual arts, moreover the machine design is hyped with the product design terms and mostly used in the field of the Automobile, Consumer electronics, Power electronics. The process of product development also show an significant effects on the life cycles of component and the process stats form the generation of idea and background research and the prototyping and testing and through analysis.

The fatigue design and testing is a concept of testing the components by the application of the repeated loads, and study the damage caused by it and estimating the service life cycles of the component. To be precise if the fatigue loading exceeds the maximum threshold material starts to crack from the nearest stress concentration point or either creates its own. Material discontinuation like holes and the fillets and chamfers enhance the life of the component., there is a theoretical value for stress amplitude below which the material will not fail for any number of cycles, called a fatigue limit, endurance limit, or fatigue strength. Engineers have used any of three methods to determine the fatigue life of a material: the stress-life method, the strainlife method, and the linear-elastic fracture mechanics method.

\section{LITERATURE REVIEW}

The numerical analysis of the stress concentration is studied by comparing the theoretical and Numerical solution in the simple geometries under different loading conditions has made by Muminovic, Adis JSaric, Isad Repcic, Nedzad[1]. Evaluation of stress concentration son the sholder fillets under varying loads has been made by the Noda, Nao-aki Takase, Yasushi Monda, Keiji[2], By incopratin of numerical methods stress concentations in the plates with holes have been made by Herrera, Francisco JavierortegaGuzman, Jose MiguelgarciaLuna, Alfonso LozanoDíaz, JavierpalaciosSalazar, Diego Armandogarcia[3], Optimisation of stress concentrations and accounting with the life is made by the N L Pedersen[4],

\section{METHODOLOGY}

In order to show the effect of the fillets in the ribbed supported bodies which are used in the household application and stiffness adders to the models used in the machines. The amount of the filleting and their corresponding effect on the product lifecycle is studied by application of the soderberg high cycle fatigue regression equation. The material applied for this study is the commonly used stainless steel and following are the properties used in this analysis. The S-N curve for the steel and aluminum are shown in below. 


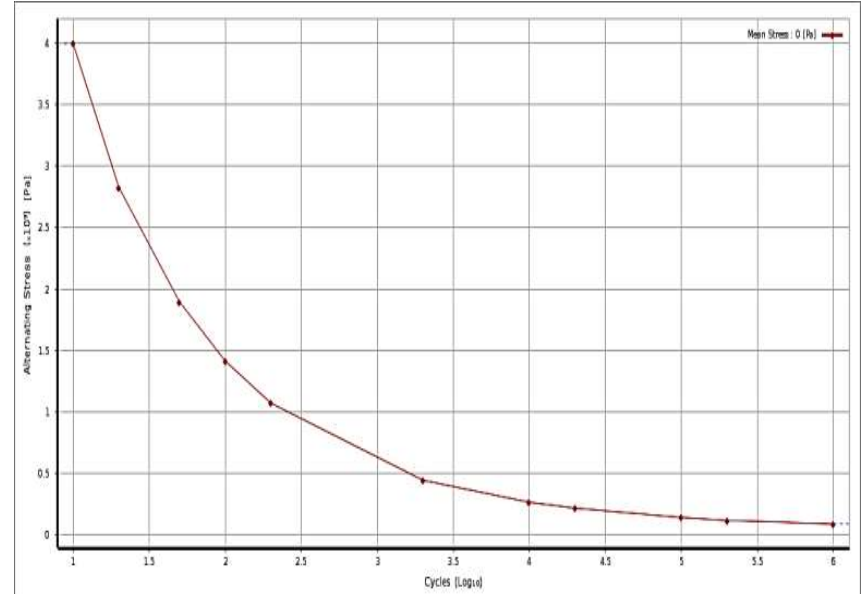

Fig 1 S-N Curve of the stainless steel in semi log axis

\subsection{Geometry of Case Study}

The study is conducted on the supporting angulars which are used for the supporting the racks, shelf partitions to me more specific. The introduction of the fillets helps in the smooth continuation of the surfaces without any sudden change in the crosection by the manufacturing process helps in the stacked arrangement of the micro structured layers which prediction of life cycles of component is made easy.

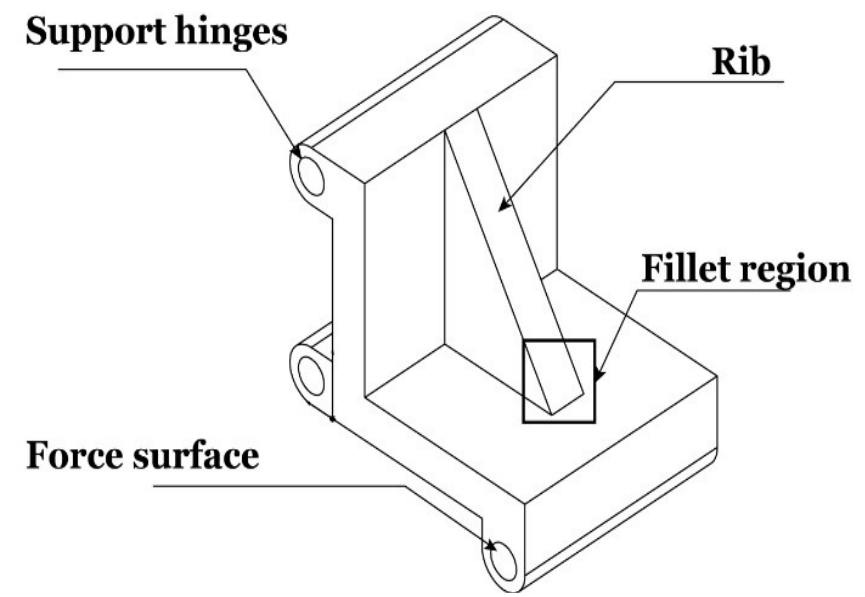

Fig 2 Design nomenclature of ribbed supported component with the fillet region

\subsection{FEA Study}

The finite element analysis is conducted with the mesh method of tetrahedrons with the total number of Number of total nodes are134504 and the Number of contact elements are 876 , and the Number of solid elements are 88725and the Number of total elements are of 89601 . The element type is chosen are solid187. The maximum Tet size was controlled by the $3 \mathrm{~mm}$. The usage of Fatigue tool helps in the specifying the analysis type of stress based, and the stress component of Equivalent stress is considering the loading type is of Fully reversed
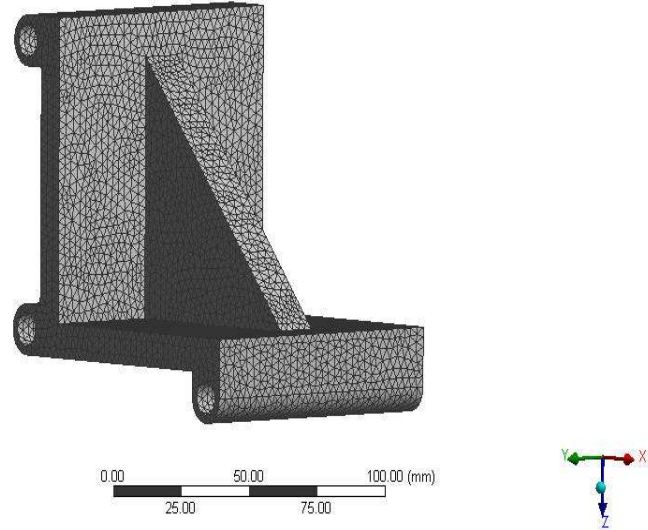

Fig 3 Tetrahedron mesh with maximum Tet size of $3 \mathrm{~mm}$,note the actual mesh is much finer than the shown

The boundary conditions applied and tested at $10000 \mathrm{~N}$ and $20000 \mathrm{~N}$.
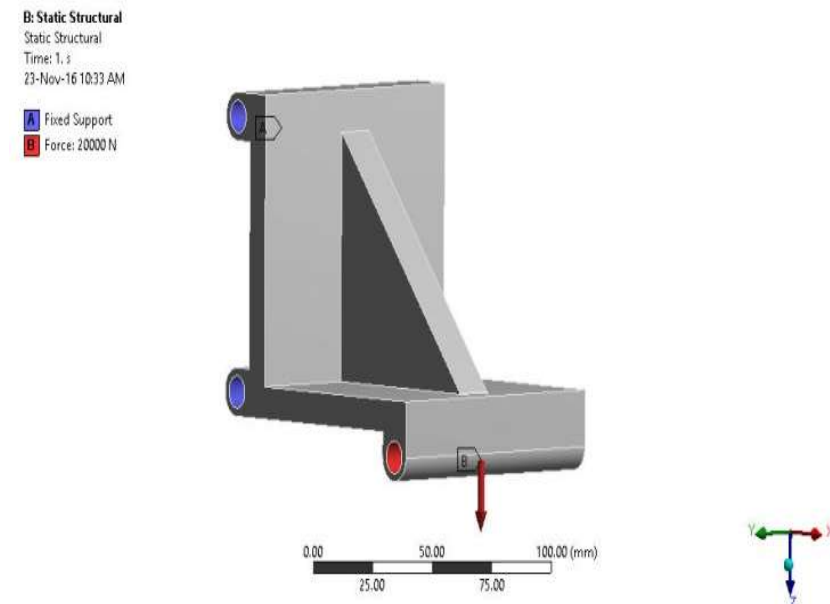

The number of the life cycles are lowered at the fillet region hence the most of the concentration of the solution was observed, by specifying the named selections.

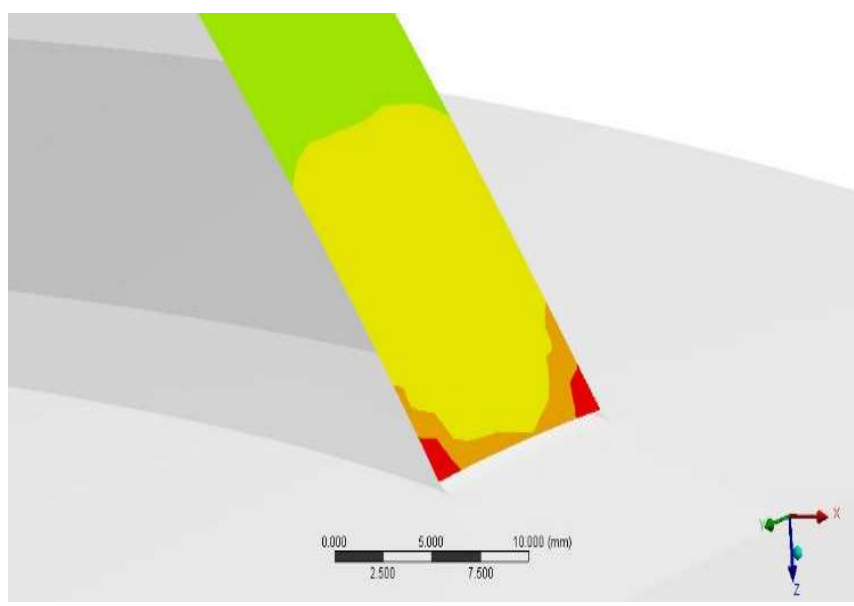

Fig 4 The maximum sensitive area where the number of life cycles are effected due to loading are taken into study. 
Since the study is fully parametric in nature the detail generation of CAD files for the all the cases is cumbersome. In order to solve this complexity, the fillets are made to parametric by dimension and changed by the scale of 5 .

\subsection{Parametric Modelling}

The main cause of reducing the number of life cycles is due to the stress concentrations so if this principle is applied to this phenomenon the parametric equation can be written as follows.

$$
N^{\prime}=f(\bar{\sigma})
$$

Where $N$ is the number of life cycles and $\bar{\sigma}$ is the stress concentration intensity,

By keeping the material as constant the equation 1 becomes as follows

$$
N^{\prime}=E_{i} \cdot f(\bar{\sigma})
$$

Where $E_{i}$ is the material young's modulus

The change in the total number of lifecycles is also dependent on the loading made hence the equation 2 becomes as follows where with increase of loading the number of life cycles are reduced.

$$
N^{\prime}=[E, v, \rho] \cdot f\left[\bar{\sigma}, \frac{1}{P}\right]
$$

Where $\mathrm{P}$ is applied load in Newtons.

The main cause of decrease in number of life cycles in our study is fillet radius hence $\bar{\sigma}$ is changed by the r.

$$
N^{\prime}=E_{i} \cdot f\left[r, \frac{1}{P}\right]
$$

To incorporate the material properties as the function of the total number of life cycles we can replace them $E_{i}$ with the material constants. Then by rewriting the equation (4) we get the following

$$
N^{\prime}=[E, v, \rho] \cdot f\left[r, \frac{1}{P}\right]
$$

On differentiating with $r$ the rate equation can be written as follows. Where $\mathrm{c}$ is known as differentiation constant.

$$
\frac{d N^{\prime}}{d r}=[E, v, \rho] \cdot f\left[\frac{1}{P}, c\right]
$$

\section{CONCLUSION}

The observations proved by the parametric analysis has followed the assumed parametric modeling and with the design having the fillet radius of combatively $50 \%$ ratio have sustained good amount of life cycles by saving the material in a economic way. But the loads are always the point of objection to justify the fillet radius. But the minimum values of life cycles is encountered rather than the maximum which have sustained the whole component to designed $10^{6}$ cycles.

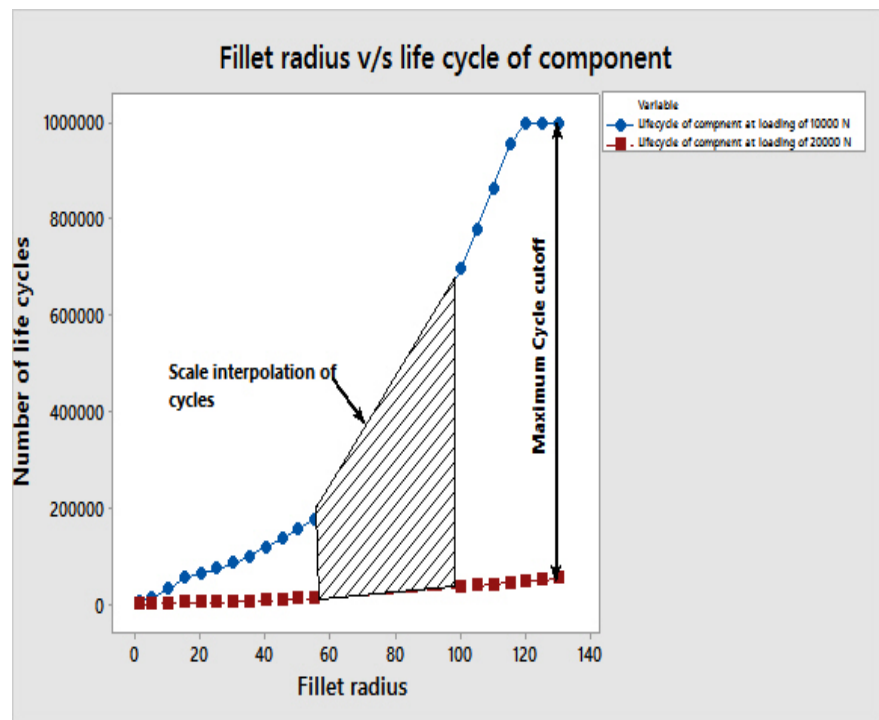

Fig 5 Plot showing the relationship between Fillet radius and Life cycle of Component with the scale interpolation and maximum cycle cutoff

The scale interpolation area between the $10000 \mathrm{~N}$ loading and $20000 \mathrm{~N}$ loading where the scale of plotting and the number of life cycles are show the parallelisms with the rate difference. This zone is purely interpolated by the scale to get the continuity of further points and there is a maximum cutoff in number of cycles say drop in cycles by the applied loads which mimics the parametric equation.

The cubic equation that was fitted for the two test cases are as follows.

$$
N^{\prime}=49631-3789 \cdot r+159.21 \cdot r^{2}-0.539 \cdot r^{3}(7)
$$

For which constant load of $10000 \mathrm{~N}$ and the for $20000 \mathrm{~N}$ loading the following equation is obtained

$$
N^{\prime}=1939+118.7 \cdot r+2.224 \cdot r^{2}+0.00007 \cdot r^{3}
$$

On differentiating equation (7) we get the rate equation as follows.

$$
\frac{d N^{\prime}}{d r}=318.42 \cdot r-1.31 \cdot r^{2}-3789
$$


On differentiating equation (8) the rate equation for $20000 \mathrm{~N}$

loading is given as follows.

$$
\frac{d N^{\prime}}{d r}=4.48 \cdot r+2.1 \times 10^{-4} \cdot r^{2}+118.7
$$

Which above equations 9,10 are exponential in nature

\section{REFERENCES}

[1] J. Muminovic, I. Saric, and N. Repcic, "Numerical Analysis of Stress Concentration Factors," Procedia Eng., vol. 100, pp. 707-713, 2015.

[2] N. Noda, Y. Takase, and K. Monda, “d-, A-," vol. 19, no. 1, pp. 75-84, 1997.

[3] F. J. Herrera, J. M. Guzman, A. L. Luna, J. Díaz, and D. A. Salazar, "Stress Concentration Factor for a Flat Plate with Fillets and Notches under Axial Load Using ANSYS ${ }^{\circledR}$ Software," pp. 3061-3070, 2015.

[4] N. L. Pedersen, "Stress concentrations in keyways and optimization of keyway design," vol. 45 , no. c, pp. 593604, 2010.

\section{BIOGRAPHIES}

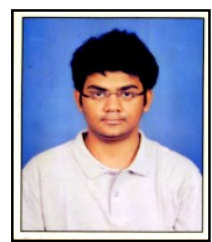

Naga Sai Ram Gopisetti is an undergraduate student studying Mechanical engineering in K L University, Having over 7 publications in the field of Industrial engineering, Cellular Manufacturing and Heat transfer. His areas of interest include Cellular manufacturing, Computer aided Engineering, and Computational Fluid Dynamics. He is part time research scholar under his guide T.Kanthimathi in field of duel cell heat exchanger

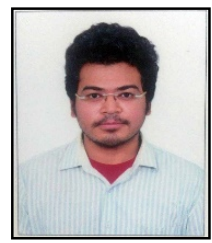

Sudhanshu G. Chouhan is an under graduate student studying the Mechanical engineering in $\mathrm{K}$ L University, His area of interest includes Industrial engineering and Automobile chaises engineering,

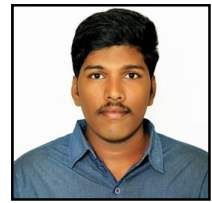

Akhil V S R Palakurthi is a an under graduate student studying the Mechanical engineering in $\mathrm{K} \mathrm{L}$ University, His area of interest includes Industrial engineering and Automobile chaises engineering, 